\title{
Cryostimulation improves recovery from oropharyngeal dysphagia after stroke
}

\author{
Patrícia Zart', Deborah Salle Levy², Geovana de Paula Bolzan ${ }^{3}$, Renata Mancopes ${ }^{4}$, Ana Maria Toniolo da Silva. \\ 1) Assistant Professor, Speech Department, Passo Fundo University, Passo Fundo/RS, Brazil \\ 2) Ph.D. in Health Science, Institute of Cardiology of Rio Grande do Sul, Adjunct Professor, Department of Psychology and Personality Development, Rio Grande do \\ Sul Federal University, Porto Alegre/RS, Brazil \\ 3) Postgraduate Student in Human Communication Disorders, Santa Maria Federal University, Santa Maria/RS, Brazil \\ 4) Ph.D. in Linguistics, Santa Catarina Federal University, Adjunct Professor, Speech Department, Santa Maria Federal University, Santa Maria, RS, Brazil \\ 5) Ph.D. in Human Communication Disorders, Sao Paulo Federal University. Associate Professor, Speech Department, Santa Maria Federal University, Santa Maria/RS, \\ Brazil \\ Institution: Universidade Federal de Santa Maria \\ Santa Maria / RS - Brazil. \\ Mailling address: Geovana de Paula Bolzan - RST 287, 6885, room 102 - Santa Maria / RS - Brazil - Zip Code: $97105-030$ - Telephone: (+55 55) 8403-5183 - E-mail: \\ gebolzan@gmail.com \\ Financial support: CAPES \\ Article received on May 11, 2012. Article accepted on October 7, 2012
}

\section{SUMMARY}

Introduction: Stroke is considered one of the most frequent neurological causes of oropharyngeal dysphagia.

Aim: To determine the effect of cryostimulation on oropharyngeal sensitivity and, subsequently, on the swallowing reaction and premature escape of food in patients with neurogenic dysphagia after stroke.

Methods: Clinical and experimental study. The study enrolled 7 adult subjects, 6 men and 1 woman ranging from 28 to 64 years of age, with a diagnosis of stroke and current oropharyngeal dysphagia without any other underlying disease. The selected subjects underwent speech-language pathology evaluation and videofluoroscopic assessment of the dysphagia. The subjects were then treated with cryostimulation consisting of 10 applications to each structure (anterior faucial pillar, posterior oropharyngeal wall, soft palate, and back tongue) 3 times a day (for a total of 30 daily applications per structure) for 4 consecutive days. The patients were then re-evaluated based on the same criteria. The pre- and post-cryostimulation results of the clinical and videofluoroscopic evaluations were analyzed descriptively and statistically using Student's t-test and Fisher's exact test.

Results: Cryostimulation had beneficial effects on oropharyngeal sensitivity in 6 of the 7 subjects. There was also a significant improvement in swallowing and in the premature escape in six subjects.

Conclusion: Cryostimulation increased sensitivity and subsequently improved the swallowing reaction and premature escape of food in patients with neurogenic dysphagia after stroke. These effects were evident by both speech-language pathology and videofluoroscopic evaluation.

Keywords: stroke; deglutition disorders; rehabilitation; cryotherapy; fluoroscopy.

\section{INTRODUCTION}

Stroke, in all of its forms, is one of the most frequent neurological causes of oropharyngeal dysphagia (1). More than $70 \%$ of patients exhibit swallowing alterations in the first days after a stroke (2), and the manifestation of dysphagia is associated with the severity of the patient's neurological condition (3).

Early diagnosis of possible swallowing disorders can lengthen the survival of patients with stroke. Speech therapy in the hospital prevents nutritional deficits and dehydration and also helps to avoid aspiration pneumonia. Furthermore, such therapy can also reduce the time spent in hospital and thus speed the patient's return to independence (1).

Video fluoroscopy, a radiological contrast examination, is used for more precise diagnosis of swallowing disorders and is considered to be the gold standard for assessment of the swallowing process. This examination allows visualization of the swallowing dynamics and identification of sub-clinical changes, which provides more comprehensive and reliable monitoring of the swallowing mechanism and helps to guide the treatment of any deficits (4).

However, the combination of anamnestic information and clinical speech evaluation of swallowing continues to be the most widely used method for assessing swallowing function. Bedside clinical evaluation allows quick identification of alterations in oral functions, e.g., an increase in oral transit or incomplete swallowing of the food bolus, alterations in vocal quality, alterations to oral reflexes, reduction of laryngeal elevation during saliva swallowing, alterations in the sensitivity of the larynx, and signs suggestive of tracheal penetration/ aspiration (5). 
Reduced oropharyngeal sensitivity is a common clinical finding upon evaluation of post-stroke neurogenic dysphagia. This reduction leads to delayed swallow triggering as well as motor and sensory alterations of the larynx (6).

Oropharyngeal sensitivity is extremely important in the swallowing process. A lack of sensitivity in this region can result in delayed oral transit, delayed triggering of the swallowing reflex, and a decreased cough reflex. It can also increase the incidence of premature escape of food into the pharynx, which risks laryngeal penetration and/or tracheal aspiration (7).

The plasticity of the central nervous system enables the adult neurological patient to recover at least partially. Repair and reorganization of the central nervous system begin spontaneously soon after the injury, and rehabilitation should therefore be started early in order to avoid further deterioration and rescue more-normal behavior patterns (8). Therapeutic techniques for rehabilitation of dysphagia can play an important role in neuroplasticity in stroke patients.

However, at present, many such techniques are used concomitantly without adequate measurement of their efficiency. Direct tactile stimulation of the pharyngeal wall is considered to be an important technique for improving the sensitivity and even the mobility of the region (9), which results in improvement of the swallowing reaction.

Such tactile stimulation of the pharyngeal wall is commonly used in combination with cold stimulus during rehabilitation from dysphagia. Short touches of a cold laryngeal mirror on the lower third of the palatoglossal arch are used to increase the intra-oral input $(10,11)$. Cryostimulation, i.e., cooling or decreasing the temperature of the tissue for therapeutic purposes, has proven to be an efficient way of regulating the sensitivity of damaged areas, including those affected by neurological injuries $(12,13)$. There is a lack of published studies of the efficiency of the various techniques used in speech therapy or how to use them for better results. Therefore, the objective of this study was to determine the effects of cryostimulation on the sensitivity of the oropharyngeal region, swallowing reaction, and premature escape of food in subjects with post-stroke neurogenic dysphagia.

\section{Methods}

This study was approved by the research ethics committee of Santa Maria Federal University (UFSM) under the number 0055.0.243.000-07 and received institutional authorization from the Hospital of Passo Fundo (HCPF), where the data were collected.

The participants in the study were adults hospitalized at HCPF and diagnosed with stroke who met the criteria of the study, and either the patients themselves or their responsible family members consented to participate and signed the Statement of Consent.

The inclusion criteria were: age up to 65 years (in order to avoid additional alterations to swallowing function due to aging), absence of oropharyngeal sensitivity to touch, presence of mild-to-moderate oropharyngeal dysphagia, sufficient alertness and understanding to participate in the therapy, premature escape of food during video fluoroscopic examination, and satisfactory tongue mobility (ability to lateralize, raise, and lower) without significant compromise of the oral route.

The exclusion criteria were: tracheostomy, previous history of swallowing difficulties, and presence of another neurological disorder that could contribute to dysphagia.

Sample selection was based on analysis of medical records, anamnesis (14) of a family member or, if possible, the subject him- or herself, clinical evaluation of dysphagia (15), and video fluoroscopic examination (16). These procedures were performed sequentially, and any potential subject excluded by one of them did not proceed to the next. Initially, 29 subjects with computed tomography (CT)based diagnoses of ischemic or hemorrhagic stroke were selected. Of these, 15 met the established inclusion and exclusion criteria, and only 7 agreed to participate in the study; these were therefore designated as the sample for convenience. The refusal of the other 8 subjects to participate was due to the increased hospitalization time that would have been required to complete the course of therapy.

The study sample was composed of 7 adults, 6 men and 1 woman aged 28 to 64 years, with a CT-based diagnosis of stroke and a diagnosis of oropharyngeal dysphagia without any other underlying disease.

\section{Data collection}

The data were collected from the evaluations used for the sample selection, which are described in detail below. Therapy was performed over 4 days, beginning on the day of the initial video fluoroscopic examination, and all evaluations were repeated on the fifth day using the same parameters considered in the initial evaluation.

Clinical speech evaluation was performed by a single trained evaluator in order to establish the presence of 
dysphagia and verify which orofacial structures were involved in the swallowing difficulties, with particular emphasis on the sensitivity and mobility of these structures. Swallowing was evaluated both indirectly (without food) and directly with $5 \mathrm{ml}$ each of liquid and paste.

The indirect evaluation emphasized the evaluation of oropharyngeal sensitivity, which was assessed by touching a wooden spatula to the pillars of the fauces, back of the tongue, soft palate, and posterior oropharynx. The absence of a reaction (such as elevation of the soft palate, a swallowing reaction or, especially, a gag reflex) to the touch was considered suggestive of hyposensitivity or complete non-sensitivity in the region $(17,18)$.

During the direct evaluation, cervical auscultation was performed using a Littman $^{\mathrm{TM}}$ stethoscope. Parameters related to the state of alertness and understanding, oral language, speech articulation, and vocal quality were also considered.

Video fluoroscopic examination was performed at HCPF by a radiology technician and a speech therapist using a Shimadzuimage intensifier (Pleno model) and following a published proposed evaluation protocol (16).

The examination was visualized live on a dual 20-inch monitor coupled to the intensifier. Sequences of images were selected and recorded on DVDs for documentation. The images displayed by this equipment are slower than real time. During the examination, the liquid and paste swallowing tests were performed with the subject seated at a $90^{\circ}$ angle, and the images were taken in the vertical plane and captured the oral cavity, lips, posterior pharyngeal wall, nasopharynx, and top opening of the upper esophageal sphincter $(12,19)$.

The examination procedure was explained to the subject, and the first image was taken with the patient at rest for calibration purposes. During the first attempt at swallowing each consistency, the patient was instructed to keep the contrast in the oral cavity until swallowing was requested in order to observe the patient's capacity to retain the contrast as well as any premature escape of food into the pharynx. In the rest of the swallows, the patient was asked to swallow as usual. The contrast was administered with a metal spoon containing $5 \mathrm{ml}$ for each swallow (19). Each subject performed a total of 10 swallows, 5 of liquid (barium water) and 5 of paste (vanilla cream with barium), for a total of $50 \mathrm{ml}$.

The images were subsequently analyzed by 3 speech therapists experienced in video fluoroscopy using the Viewerlite 2 Philips Inturis Suite Lite, v.2.1.1 (2001) program. The structures examined were divided between the oral and pharyngeal phases.

The oral phase comprised the retention capacity, movement of the tongue, premature loss of food into the pharynx, residue in the furrows, and the dorsum of the tongue, floor of the mouth, velopharyngeal closure, and oral transit time.

The pharyngeal phase comprised the swallowing reaction, elevation of the larynx, movement of the hyoid, posterior pharyngeal wave, residue in the vallecula and posterior pharyngeal wall, time of pharyngeal transit, multiple swallows, laryngeal penetration, and tracheal aspiration.

The moment at which the swallowing reaction was triggered was defined based on the literature, which indicates that the end of the oral phase is defined radiologically as the moment at which the food passes the posterior mandible, at which point the pharyngeal phase begins with anterior hyoid excursion $(12,19)$. Premature escape of food into the pharynx was defined as food passing the posterior mandible into the pharynx without triggering a swallowing reaction.

Immediately after the end of the videofluoroscopic examination, cryostimulation was performed with the objective of stimulating the oropharyngeal region and improving its sensitivity. The procedure was performed 3 times a day (17), at approximate minimum intervals of 4 hours, for 4 consecutive days. The 3 daily sessions included the faucial pillars, posterior oropharyngeal wall, soft palate, and back tongue. The stimulus was applied 10 times to each structure in each session, for a subtotal of 30 applications to each structure each day and a total of 480 applications over the entire course of therapy.

Cryostimulation was performed using a cold laryngeal mirror that was immersed in crushed ice for 10 minutes before the start of each stimulation session in order to attain a near-optimal temperature, which was approximately $11^{\circ} \mathrm{C}$ for this purpose. After 3 seconds, the mirror was reimmersed in the ice for a maximum of 3 seconds and then re-applied to the structure. After each set of 10 applications to each structure, the subject was stimulated to induce saliva swallowing (17).

The handle of the mirror was insulated with polystyrene foam material to prevent conduction of the speech therapist's body heat and thus premature warming of the mirror during the manipulation. Such a lining is necessary to maintain a neutral temperature for up to 5 seconds after removal of the mirror from the ice (20). The 3-second application time was chosen to minimize the risk that the mirror would warmbeyond the desired temperature $(12,21)$. 
Cryostimulation depends on physical factors related to the conduction of heat from one body to another. The time for which the object must be immersed in the ice to achieve the desired temperature for the particular set of working conditions and object material used in this study was determined to be 10 minutes according to thermodynamic analysis by a mechanical engineer in a specific laboratory. The following parameters were considered in the analysis: the approximate room temperature, human body temperature, size of the mirror handle area, size of the mirror area in contact with the oral cavity, quantity of ice for cooling the object, quantity needed to reduce the heat of the instrument, flow of heat from the ice to the tool, and flow of heat from the tool to the body.

\section{Data analysis}

The data were analyzed by comparing the findings of the clinical and videofluoroscopic evaluations before and after cryostimulation. The statistical significance of these results was determined using Fisher's exact test for small samples with a $\mathrm{p}$ value $<0.05$ considered to indicate significance.

For the analysis of the swallow time from the video fluoroscopic examination, 3 of the 5 swallows were selected. The following aspects of each swallow were analyzed: the total time of swallowing (TTD), time for oral transit until the swallowing reaction (TTO-RD), and time for pharyngeal transit from the swallowing reaction until pharyngeal clearance (TTF-LF).

In order to identify the anatomic site at which the swallowing reaction was initiated during the visualization of the images by the analysis program on the laptop computer, the site of swallow initiation was marked on the screen using a green pen compactor OHP permanente $M$.

The TTD, TTO-RD, and TTF-LF were determined as follows. The times were measured using a Casio chronometer that allowed measurement of centiseconds (1/100 s). To obtain the most accurate results, each swallow was analyzed and each part of the swallow timed 20 times. Then, there were three timed swallowing tests and their values were used to average the times obtained. It is important to highlight that the values obtained in seconds and centiseconds are longer than the actual swallowing times, as the images were not obtained in real time, and are therefore only used for comparing the times before and after cryostimulation therapy.

We determined the TTD, TTO-RD, and TTF-LF for each swallow consistency for each subject and compared the values obtained before and after cryostimulation. The values were compared and their statistical significance determined using Student's t-test with a significance level of $5 \%(\mathrm{p}<0.05)$.

A second trained evaluator repeated the entire analysis of a randomly selected subject (subject 2), and these values were used to calculate the level of interobserver concordance. A point-to-point correlation of the 2 sets of measurements was performed, and the values obtained indicated acceptable inter-trial reliability. This additional evaluator used the same materials used by the previous evaluators.

The inter-evaluator reliability was measured 20 days later using a random sample of $10 \%$ of the total number of swallows. Analysis of this set of swallows by the same criteria used for the original analysis revealed that the measurements were comparable.

\section{RESUlts}

Table 1 shows the clinical characteristics of the study sample obtained from the anamnesis and records, including each subject's sex, age, underlying disease, affected hemisphere, expressive and comprehensive language ability, presence of pneumonia, mode of alimentation, and food consistency.

The results obtained before and after the performance of cryostimulation therapy for all of the subjects are shown according to the evaluation. Figure 1 shows the results of the oropharyngeal sensitivity testing in the clinical evaluation. Table 2 shows the other results of the clinical speech evaluation. Tables 3 and 4 show the results obtained by video fluoroscopic evaluation of the oral and pharyngeal phases of swallowing, respectively, and Table 5 shows the swallowing time data.

Oropharyngeal sensitivity was absent in all of the subjects at the time of the initial evaluation, as this was one of the inclusion criteria for the study. This parameter improved significantly after cryostimulation $(p=0.002)$, as shown in Figure 1.

Clinical evaluation (Table 2) showed that the swallowing reaction and cervical auscultation results for both of the tested consistencies improved significantly after cryostimulation. The frequencies of wet voice, coughing/ choking, and signs suggestive of tracheal aspiration associated with swallowing the liquid also decreased.

Video fluoroscopic examination showed no significant differences in the oral phase of swallowing after cryostimulation (Table 3). In contrast, improvements in 
Table I. Characterization of the study subjects in terms of sex, age, underlying disease, hemispheric lesion, expressive and comprehensive language, presence of pneumonia, mode of alimentation, and food consistency.

\begin{tabular}{|c|c|c|}
\hline VARIABLE & $n^{\circ}$ & $\%$ \\
\hline \multicolumn{3}{|l|}{ SEX } \\
\hline Female & । & 14.29 \\
\hline Male & 6 & 85.71 \\
\hline \multicolumn{3}{|l|}{ AGE } \\
\hline 20-40 years & 2 & 28.57 \\
\hline $4 \mid-60$ years & 3 & 42.86 \\
\hline $61-70$ years & 2 & 28.57 \\
\hline \multicolumn{3}{|l|}{ UNDERLYINGDISEASE } \\
\hline Stroke $(I)$ & 6 & 86.71 \\
\hline Stroke $(H)$ & । & 14.29 \\
\hline \multicolumn{3}{|l|}{ HEMISPHEREAFFECTED } \\
\hline RightHemisphere & 3 & 42.86 \\
\hline LeftHemisphere & 3 & 42.86 \\
\hline Brainstem & । & 14.28 \\
\hline \multicolumn{3}{|l|}{ EXPRESSIVE LANGUAGE } \\
\hline Dysarthria & । & 14.29 \\
\hline Aphasia & 4 & 57.14 \\
\hline Noalteration & 2 & 28.57 \\
\hline \multicolumn{3}{|l|}{ COMPREHENSIVELANGUAGE } \\
\hline Present & 4 & 57.14 \\
\hline Reduced & 3 & 42.86 \\
\hline Absent & 0 & 0 \\
\hline \multicolumn{3}{|l|}{ PNEUMONIA } \\
\hline Present & 4 & 5.14 \\
\hline Absent & 3 & 42.86 \\
\hline \multicolumn{3}{|l|}{ MODE OFALIMENTATION } \\
\hline Probe & 2 & 28.57 \\
\hline Oral & 4 & 57.14 \\
\hline Oral with orientation & । & 14.29 \\
\hline \multicolumn{3}{|l|}{ FOOD CONSISTENCY } \\
\hline Difficulty with liquid & 3 & 42.86 \\
\hline Difficulty with paste & । & 14.29 \\
\hline Difficulty with liquid and paste & l & 14.29 \\
\hline Difficulty with solids & I & 14.29 \\
\hline
\end{tabular}

Legend: Stroke (I): ischemic stroke; Stroke (H): hemorrhagic stroke.

several aspects of the pharyngeal phase during swallowing of both liquid and paste (Table 4), including pharyngeal transit, the swallowing reaction, and the occurrence of premature escape of food, as well as elimination of laryngeal penetration of liquids in all of the patients in whom it had previously occurred, were observed after cryostimulation therapy.

Table 5 shows the distribution of the means and standard deviations of the swallowing times for both consistencies, divided into the total swallowing time, oral transit time until

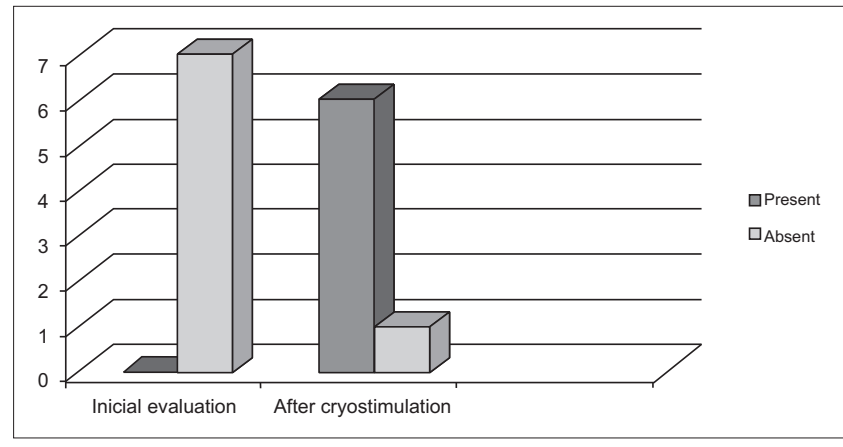

Figure 1. Evaluation of oropharyngeal sensitivity before and after cryostimulation.

the Swallowing reaction, and pharyngeal transit time from the swallowing reaction until pharyngeal clearance. The mean total swallowing time (TTD) and the oral transit time until the swallowing reaction (TTO-RD) for the paste swallows decreased after cryostimulation. The mean time for pharyngeal transit from the swallowing reaction until pharyngeal clearance (TTF-LF) for the liquid swallows increased after cryostimulation.

\section{DISCUSSION}

The clinical manifestations of dysphagia after stroke vary according to the size and location of the lesion, but some of the more frequently encountered signs are reduced sensitivity in the oropharyngeal region, delayed triggering of the swallowing reflex, and reduced pharyngeal contraction. Another important manifestation is a decreased coughing reflex, which can also occur in response to a loss of laryngeal sensitivity (22). If not recognized and treated in a timely fashion, all of these manifestations can cause have serious consequences, such as aspiration pneumonia, malnutrition, and even death, in patients with dysphagia after stroke.

Therefore, a deep knowledge of the effects of various therapeutic techniques on each stage of swallowing is essential to shorten the rehabilitation process and reduce the risks of dysphagia.

The results of this study showed that cryostimulation, a thermal-tactile technique, improved the oropharyngeal sensitivity, swallowing reaction, and premature escape of food in patients with dysphagia after stroke. These findings agree with published results that cryostimulation can increase local sensitivity and probably reduce the premature escape of food by decreasing the swallowing reaction time $(10,11)$. 
Table 2. Results of the direct speech evaluation, using liquid and paste, of the 7 subjects before and after cryostimulation.

\begin{tabular}{|c|c|c|c|c|c|c|c|c|c|c|}
\hline \multirow[t]{3}{*}{ Variable } & \multicolumn{4}{|c|}{ Liquid } & \multicolumn{6}{|c|}{ Paste } \\
\hline & \multicolumn{2}{|c|}{ Before } & \multicolumn{2}{|c|}{ After } & \multirow[t]{2}{*}{ p } & \multicolumn{2}{|c|}{ Before } & \multicolumn{2}{|c|}{ After } & \multirow[t]{2}{*}{$p$} \\
\hline & $\mathrm{n}$ & $\%$ & $n$ & $\%$ & & $n$ & $\%$ & $\mathrm{n}$ & $\%$ & \\
\hline \multicolumn{11}{|l|}{ AVL } \\
\hline Yes & 2 & 28.57 & 1 & 14.29 & \multirow[t]{3}{*}{0.5} & 2 & 28.57 & I & 14.29 & \multirow[t]{3}{*}{0.5} \\
\hline No & 5 & 71.43 & 6 & 85.71 & & 5 & 71.43 & 6 & 85.71 & \\
\hline \multicolumn{9}{|l|}{ EOA } & & \\
\hline Yes & 2 & 28.57 & I & 14.29 & \multirow[t]{3}{*}{0.5} & I & | 4.29 & 0 & 0 & \multirow[t]{3}{*}{0.5} \\
\hline No & 5 & 71.43 & 6 & 85.71 & & 6 & 85.71 & 7 & 100 & \\
\hline \multicolumn{9}{|l|}{ TTOA } & & \\
\hline Yes & 2 & 28.57 & I & | 4.29 & \multirow[t]{2}{*}{0.5} & 5 & 71.43 & 2 & 28.57 & \multirow[t]{2}{*}{0.14} \\
\hline No & 5 & 71.43 & 6 & $85.7 \mid$ & & 2 & 28.57 & 5 & 71.43 & \\
\hline \multicolumn{11}{|l|}{ RDA } \\
\hline Yes & 7 & 100 & I & 14.29 & \multirow[t]{2}{*}{0.002} & 7 & 100 & I & 14.29 & \multirow[t]{2}{*}{0.002} \\
\hline No & 0 & 0 & 6 & 85.71 & & 0 & 0 & 6 & $85.7 \mid$ & \\
\hline \multicolumn{11}{|l|}{ REL } \\
\hline Yes & 4 & 57.14 & 3 & 42.86 & \multirow[t]{2}{*}{0.5} & 4 & 57.14 & 3 & 42.86 & \multirow[t]{2}{*}{0.5} \\
\hline No & 3 & 42.86 & 4 & 57.14 & & 3 & 42.86 & 4 & 57.14 & \\
\hline$M D$ & & & & & & & & & & \\
\hline Yes & 5 & 71.43 & 4 & 57.14 & 0.5 & 5 & 71.43 & 4 & 57.14 & 0.5 \\
\hline No & 2 & 28.57 & 3 & 42.86 & & 2 & 28.57 & 3 & 42.86 & \\
\hline RN & & & & & & & & & & \\
\hline Yes & I & 14.29 & 0 & 0 & 0.5 & 0 & 0 & 0 & 0 & $=$ \\
\hline No & 6 & 85.71 & 7 & 100 & & 7 & 100 & 7 & 100 & \\
\hline AAC & & & & & & & & & & \\
\hline Yes & 6 & 85.71 & 0 & 0 & 0.002 & 4 & 57.14 & 0 & 0 & 0.03 \\
\hline No & I & 14.29 & 7 & 100 & & 3 & 42.86 & 7 & 100 & \\
\hline$V M$ & & & & & & & & & & \\
\hline Yes & 6 & 85.71 & I & 14.29 & 0.01 & 3 & 42.86 & 0 & 0 & 0.09 \\
\hline No & I & 14.29 & 6 & 85.71 & & 4 & 57.14 & 7 & 100 & \\
\hline $\mathrm{T} / \mathrm{E}$ & & & & & & & & & & \\
\hline Yes & 7 & 100 & 2 & 28.57 & 0.01 & 5 & 71.43 & 2 & 28.57 & 0.14 \\
\hline No & 0 & 0 & 5 & 71.43 & & 2 & 28.57 & 5 & 71.43 & \\
\hline SSPL & & & & & & & & & & \\
\hline Yes & 6 & $85.7 \mid$ & 0 & 0 & 0.002 & 3 & 42.86 & 0 & 0 & 0.09 \\
\hline No & I & 14.29 & 7 & 100 & & 4 & 57.14 & 7 & 100 & \\
\hline SSAT & & & & & & & & & & \\
\hline Yes & 0 & 0 & 0 & 0 & $=$ & 0 & 0 & 0 & 0 & $=$ \\
\hline No & 7 & 100 & 7 & 100 & & 7 & 100 & 7 & 100 & \\
\hline
\end{tabular}

Level of significance, $5 \%(\mathrm{p}<0.05)$; Legend: AVL $=$ labial alteration, EOA $=$ oral anterior escape, TTOA $=$ increased time for oral transit, $\mathrm{RDA}=$ delayed swallowing reaction, $\mathrm{REL}=$ reduction in laryngeal elevation, $\mathrm{MD}=$ multiple swallows, $\mathrm{RN}=$ nasal reflux, $\mathrm{AAC}=$ alteration in cervical auscultation, $\mathrm{T} / \mathrm{E}=$ coughing/choking, $\mathrm{VM}=$ wet voice, $\mathrm{SSPL}=$ signs suggestive of laryngeal penetration, and SSAT $=$ signs suggestive of tracheal aspiration.

The plasticity of the cells of the central nervous system during both development and pathological processes is known to be affected by the peripheral stimulation captured and conducted by sensory systems. The sensory area receives, decodes, and analyzes the stimuli, the motor area controls the conscious and voluntary movements, and the associative area integrates the information from the sensory and motor areas to plan the types of movements and behaviors most appropriate for the situation (23). Therefore, the objective of the therapy is to provide the needed stimuli so that the central nervous system can interpret the information coming from the periphery and process and integrate it with the other areas in a way that enables reorganization of afferents and lowers the thresholds of response $(8,23,24)$.

Therefore, oropharyngeal sensitivity, as represented by the gag reflex elicited during the indirect clinical evaluation, 
Table 3. Results of video fluoroscopic evaluation of the oral phase of swallowing of liquid and paste before and after cryostimulation

\begin{tabular}{|c|c|c|c|c|c|c|c|c|c|c|}
\hline \multirow[t]{3}{*}{ Variable } & \multicolumn{4}{|c|}{ Liquid } & \multicolumn{6}{|c|}{ Paste } \\
\hline & \multicolumn{2}{|c|}{ Before } & \multicolumn{2}{|c|}{ After } & \multirow[t]{2}{*}{$\mathrm{P}$} & \multicolumn{2}{|c|}{ Before } & \multicolumn{2}{|c|}{ After } & \multirow[t]{2}{*}{$\mathrm{p}$} \\
\hline & $n$ & $\%$ & $n$ & $\%$ & & $n$ & $\%$ & $n$ & $\%$ & \\
\hline \multicolumn{11}{|l|}{ TO } \\
\hline Increased & 3 & 42.86 & 0 & 0 & 0.5 & 5 & 71.43 & 2 & 28.57 & 0.14 \\
\hline $\begin{array}{l}\text { Adequate } \\
\mathrm{RCO}\end{array}$ & 4 & 57.14 & 7 & 100 & & 2 & 28.57 & 5 & 71.43 & \\
\hline Present & 5 & 71.43 & 5 & 71.43 & 0.72 & 7 & 100 & 7 & 100 & 0.5 \\
\hline Absent & 2 & 28.57 & 2 & 28.57 & & 0 & 0 & 0 & 0 & \\
\hline
\end{tabular}

Level of significance, $5 \%(\mathrm{p}<0.05)$; Legend: $\mathrm{TO}=$ oral transit, $\mathrm{RCO}=$ residue in oral cavity.

Table 4. Results of video fluoroscopic evaluation of the pharyngeal phase of swallowing of liquid and paste before and after cryostimulation

\begin{tabular}{|c|c|c|c|c|c|c|c|c|c|c|}
\hline \multirow[t]{3}{*}{ Variable } & \multicolumn{4}{|c|}{ Liquid } & \multicolumn{6}{|c|}{ Paste } \\
\hline & \multicolumn{2}{|c|}{ Before } & \multicolumn{2}{|c|}{ After } & \multirow[t]{2}{*}{$\mathrm{p}$} & \multicolumn{2}{|c|}{ Before } & \multicolumn{2}{|c|}{ After } & \multirow[t]{2}{*}{$\mathrm{p}$} \\
\hline & $n$ & $\%$ & $n$ & $\%$ & & $\mathrm{n}$ & $\%$ & $n$ & $\%$ & \\
\hline \multicolumn{11}{|l|}{ TF } \\
\hline Increased & 5 & 71.43 & 0 & 0 & 0.01 & 4 & 57.14 & 0 & 0 & 0.03 \\
\hline Adequate & 2 & 28.57 & 7 & 100 & & 3 & 42.86 & 7 & 100 & \\
\hline \multicolumn{11}{|l|}{ EP } \\
\hline Present & 7 & 100 & I & 14.29 & 0.002 & 7 & 100 & 1 & 14.29 & 0.002 \\
\hline Absente & 0 & 0 & 6 & 85.71 & & 0 & 0 & 6 & 85.71 & \\
\hline \multicolumn{11}{|l|}{$\mathrm{RD}$} \\
\hline Delayed & 7 & 100 & I & 14.29 & 0.002 & 7 & 100 & I & 14.29 & 0.002 \\
\hline Adequate & 0 & 0 & 6 & 85.71 & & 0 & 0 & 6 & 85.71 & \\
\hline \multicolumn{11}{|l|}{ EL } \\
\hline Reduced & I & 14.29 & 0 & 0 & 0.5 & 5 & 71.43 & 3 & 42.86 & 0.29 \\
\hline Adequate & 6 & 85.71 & 7 & 100 & & 2 & 28.57 & 4 & 57.14 & \\
\hline \multicolumn{11}{|l|}{$E$} \\
\hline Present & 6 & 85.7। & 4 & 57.14 & 0.28 & 7 & 100 & 5 & 71.43 & 0.23 \\
\hline Absent & 1 & 14.29 & 3 & 42.86 & & 0 & 0 & 2 & 28.57 & \\
\hline \multicolumn{11}{|l|}{ PL } \\
\hline Present & 6 & 85.71 & 0 & 0 & 0.002 & 3 & 42.86 & 0 & 0 & 0.09 \\
\hline Absent & I & 14.29 & 7 & 100 & & 4 & 57.14 & 7 & 100 & \\
\hline \multicolumn{11}{|l|}{ AT } \\
\hline Present & 0 & 0 & 0 & 0 & - & 0 & 0 & 0 & 0 & - \\
\hline Absent & 7 & 100 & 7 & 100 & & 7 & 100 & 7 & 100 & \\
\hline
\end{tabular}

Level of significance, $5 \%(\mathrm{p}<0.05)$; Legend: $\mathrm{TF}=$ pharyngeal transit, $\mathrm{EP}=$ premature escape, $\mathrm{RD}=$ swallowing reaction, $\mathrm{EL}=$ laryngeal elevation, $\mathrm{E}=$ stasis, $\mathrm{PL}=$ laryngeal penetration, $\mathrm{AT}=$ tracheal aspiration

Table 5. Distribution of the means and standard deviations of the swallowing times for liquid and paste measured before and after cryostimulation.

\begin{tabular}{lcccccc}
\hline Variable & & Liquid & \multicolumn{3}{c}{ Paste } \\
& Before & After & $p$ & Before & After & $P$ \\
\hline TTD & $2.70( \pm 1.02)$ & $2.43( \pm 0.59)$ & 0.177 & $3.81( \pm 0.97$ & $3.26( \pm 0.86)$ & 0.0006 \\
TTO-RD & $1.91( \pm 0.98)$ & $1.54( \pm 0.45)$ & 0.11 & $2.91( \pm 0.96)$ & $2.23( \pm 0.80)$ & 0.0019 \\
TTF-LF & $0.73( \pm 0.18)$ & $0.95( \pm 0.24)$ & 0.0016 & $0.88( \pm 0.08)$ & $1.09( \pm 0.17)$ & 0.01 \\
\hline
\end{tabular}

Level of significance, $5 \%(\mathrm{p}<0.05)$; Legend: TTD $=$ total swallowing time, $\mathrm{TTO}-\mathrm{RD}=$ oral transit time until the swallowing reaction, and TTF-LF $=$ pharyngeal transit time of the swallowing reaction until pharyngeal clearance. 
was considered the most relevant variable of the study. After therapy, the gag reflex in response to touch reappeared in 6 subjects and remained absent in only 1 . These results confirmed the hypothesis that cold thermal stimulation as well as sour taste influence the dynamic modulation of swallowing and may positively impact the rehabilitation of individuals with oropharyngeal dysphagia (25).

An abnormal or absent gag reflex is considered a sign of dysphagia $(26,27)$, and such signs occur frequently in patients with stroke sequelae (28). However, the literature shows no direct relationship between oropharyngeal sensitivity and decreased gag reflex as factors that can contribute to delaying the swallowing reaction.

The results of the functional clinical evaluation of swallowing of liquid and paste generally showed that the therapy produced important changes in the variables studied.

Before cryostimulation, the swallowing reaction during alimentation with liquid and paste was delayed in all 7 subjects. This parameter improved after therapy, indicating that cryostimulation increased the swallowing response and corroborating the findings of other studies $(12,17,29,30)$. However, some authors report that cold used in isolation does not affect swallowing and show that combined techniques, such as cold and citric acid (31) or cold, mechanical, and gustatory (21) stimuli applied together would be more efficient.

Today, we know that the beginning of the pharyngeal phase of swallowing may vary even among healthy adult individuals and may be located in the oral cavity, oropharynx, or hypopharynx $(32,33)$. Therefore, we question the conventional wisdom that the palatoglossal pillars are the main location of the receptors responsible for initiating the pharyngeal phase of swallowing, which is the basis for the use of the mechanical-thermal maneuver to stimulate the receptors in these pillars (34). Pharyngeal responses to the beginning of swallowing can be induced by stimulating different sensory sites (32). However, the results of the present study show that although the palatoglossal pillars are not the only or even the predominant sensory site, stimulation of these structures improves pharyngeal sensitivity in patients with neurological deficits after stroke.

Cervical auscultation findings also improved for swallowing of both liquid and paste, which is attributable to the improvement in the swallowing reaction enabling the food to be swallowed without the laryngeal penetration observed during the initial evaluations. This would also explain the reduction in the occurrence of wet voice, a related parameter that also significantly improved after cryostimulation. We believed that these latter aspects have not had significant improvement in intake of pasty consistency, because the paste consistency had less change than the other consistencies, already in the initial evaluation.

The video fluoroscopic examination showed no difference in the oral phase of swallowing (as represented by the oral transit time and residue in the oral cavity) after cryostimulation therapy. Although the literature reports that cold stimulation reduces the oral transit time (12), we did not observe this effect. The presence of residue in the oral cavity was also unaffected by the stimulation. These findings can probably be explained by the fact that in the oral phase, reduced tongue mobility can limit the manipulation of food and even complicate the propulsion of the food bolus, actions that are not targeted by cryostimulation as performed in this study.

In the pharyngeal phase, the video fluoroscopic examination after cryostimulationshowed improvements in the pharyngeal transit, swallowing reaction, and occurrence of premature escape of food for both the liquid and the paste as well as the elimination of laryngeal penetration of the liquid.

The improvement in the pharyngeal transit time in response to cryostimulation shown in this study was also observed in other studies $(29,35)$. This finding can be explained by the improvement in the swallowing reaction, as these parameters are related (19).

The premature escape of food and the delayed swallowing reaction were present for both food consistencies in all of the study subjects in the initial evaluation and improved significantly after cryostimulation, probably due to the increased oropharyngeal sensitivity (17). These results agree with published data showing that cold therapy is an efficient technique for improving the swallowing reaction $(12,17,29,30)$.

The results of videofluoroscopy concurred with those of the clinical evaluation, showing agreement between the evaluation tools used in this study.

Cryostimulation significantly decreased the laryngeal penetration of liquid, as the final evaluation did not show laryngeal penetration in any of the study subjects. This can be explained as a consequence of the improvement in the swallowing reaction and reduction of the premature escape of food, because a delay in the triggering of swallowing and the premature escape of food can allow laryngeal penetration and/or tracheal aspiration.

We analyzed the total swallowing time, oral transit time until the swallowing reaction, and time for pharyngeal transit from the swallowing reaction until pharyngeal clearance. These measures are important because adult 
patients with dysphagia after stroke usually exhibit a prolonged transition between the end of the oral phase and the beginning of the pharyngeal phase with premature escape and delayed swallowing reactions, which facilitate aspiration (19).

We observed that the average total swallowing time and the oral transit time until the swallowing reaction decreased after cryostimulation only for the swallowing of paste. These results show that cryostimulation was able to improve the swallowing reaction and agree with the findings of previous studies that used cryostimulation in subjects with oropharyngeal dysphagia caused by stroke $(12,17)$.

The average pharyngeal transit time from the swallowing reaction until pharyngeal clearance for the liquid swallows increased after cryostimulation therapy. This apparently contradictory delay may be related to the persistence of liquid stasis even after therapy. This is attributable to the fact that even after improvement in the swallowing reaction, the subjects probably required a greater number of swallows to completely clear food residue from the pharynx, thus increasing the pharyngeal transit time from the swallowing reaction until complete pharyngeal clearance. It should be noted that we evaluated neither the number of swallows nor the occurrence of multiple swallows, which is a limitation of this study.

The small size of the sample can also be considered a limitation of this study; however, the results showed statistically significant improvements in the parameters that were the main focus of this research. The study shows that this technique, the efficacy of which has been questioned, can be an important resource for speech therapy of post-stroke patients. It also shows the importance of the criteria used in the methodology, the tools selected, and, more specifically in this case, the achievement of the appropriate temperature based on the physical science of heat conduction.

Spontaneous recovery of the central nervous system during the therapy period may have contributed to the study subjects' improvements in swallowing $(8,23)$, but we believe that early intervention aided and enhanced the improvement in this period by providing peripheral stimulation to assist synaptic recovery.

\section{CONCLUSION}

In this study, cryostimulation therapy produced recovery of oropharyngeal sensitivity as well as improvements in the swallowing reaction and the premature escape of food during swallowing of both liquid and paste in patients with neurological dysphagia after stroke.

\section{REFERENCES}

1. Abdulmassih EM, Macedo Filho ED, Santos RS, Jurkiewicz AL. Evolução de pacientes com disfagia orofaríngea em ambiente hospitalar. Arq Int Otorrinolaringol. 2009;13(1):5562.

2. Schelp AO, Cola PC, Gatto AR, Silva RG, Carvalho LR. Incidência de disfagia orofaríngea após acidente vascular encefálico em hospital público de referência. Arq Neuropsiquiatr. 2004;62(2-B):503-506.

3. Itaquy BR, Favero SR, Ribeiro MC, Barea LM, Almeida ST, Mancopes R. Dysphagia and cerebrovascular accident: relationship between severity degree and level of neurological impairment.J Soc Bras Fonoaudiol. 2011;23(4):385-9.

4. Costa MMB. Videofluoroscopy: the gold standard exam for studying swallowing and its dysfunction. Arq Gastroenterol. 2010;47(4): 327-8.

5. Padovani AR, Moraes DP, Mangili LD, Andrade CRF. Protocolo Fonoaudiológico de Avaliação do Risco para Disfagia (PARD). Rev Soc Bras Fonoaudiol. 2007;12(3):199205.

6. Gallas S, Marie JP, Leroi AM, Verin E. Sensory transcutaneous electrical stimulation improves post-stroke dysphagic patients. Dysphagia. 2010;25:291-29.

7. Furkim AM. Fonoterapia nas disfagias orofaríngeas neurogênicas. In: Furkim AM, Santini SC. Disfagias orofaríngeas. São Paulo: Pró-Fono; 1999. p. 229-58.

8. Oliveira CEN, Salina ME, Annunciato NF. Fatores ambientais que influenciam a plasticidade do sistema nervoso central. Acta Fisiatr. 2001;8(1):6-13.

9. Miller RM, Groher ME. General treatment of neurologic swallowing disorders. Dysphagia. 1992; 8:197-217.

10. Gielow I. Reabilitação fonoaudiológica na disfagia em pós-operatório de cirurgia de cabeça e pescoço.In: Furkim AM, Santini SC. Disfagias orofaríngeas. São Paulo: Pró-Fono; 1999. p. 203-28.

11. Pereira NAV, Motta AR, Vicente LCC. Reflexo da deglutição: análise sobre eficiência de diferentes estímulos em jovens sadios. Pró-Fono. 2008;20(3):159-64.

12. RosenbekJC, Roecker EB, Wood JL, Robbins J. Thermal application reduces the duration of stage transition in dysphagia after stroke. Dysphagia. 1996;11:225-33. 
13. Rodriguez EM, Guimarães CS. Manual de Recursos Fisioterapeuticos. Rio de Janeiro: Revinter, 1988.

14. Silva RG. Disfagia Neurogênica em Adultos: uma proposta para avaliação clínica. In: Furkim AM, Santini SC. Disfagias orofaríngeas. São Paulo: Pró-Fono; 1999. p.35-48.

15. Silva RG, Gatto AR, Cola PC. Disfagia orofaríngea neurogênica emadultos-avaliação fonoaudiológica em leito hospitalar. In: Jacobi JS, Levy DS, Silva LMC. Disfagia avaliação e tratamento. Rio de Janeiro: Revinter; 2003. p. 181-93.

16. Gonçalves, MIR. Vidigal MLN. Avaliação videofluoroscópica das disfagias. In: Furkim AM, Santini SC. Disfagias orofaríngeas. São Paulo: Pró-Fono; 1999. p.189202.

17. Manrique D. Avaliação otorrinolaringológica da deglutição. In: Furkim AM, Santini SC. Disfagias orofaríngeas. São Paulo: Pró-Fono; 1999. p.49-60.

18. Logemann JA. Evaluation and treatment of swallowing disorders. San Diego, CA, College-Hill Press, 1983.

19. Kim Y, McCullough GH. Stage Transition Duration in Patients Poststroke, Dysphagia. 2007;22:299-305.

20. Selinger M, Prescott TE, Hoffman I. Temperature acceleration in cold oral stimulation. Dysphagia. 1994;9:8387 .

21. Sciortino KF, Liss JM, Case JL, Gerrirsen KGM, Katz RC. Effects of mechanical, cold, gustatory and combineted stimulation to the human anterior faucial pillars. Dysphagia. 2003;18:16-26.

22. Buchholz D, Robbins J. Neurologic diseases affecting oropharingeal swallowing. In: Perlman A. Schulze-Delrieu K. Deglutition and its disorders. San Diego, Singular Publishing Group, 1997.

23. Robbins J, Butler SG, Daniels SK, Diez Gross R, Langmore S, Lazarus CL et al. Swallowing and dysphagia rehabilitation: translating principles of neural plasticity into clinically oriented evidence. J. Speech Lang. Hear Res. 2008;51(1):276-300.
24. Carr J, Shepherd R. Ciência do movimento: fundamentos para fisioterapia na reabilitação. 2. ed. Barueri: Manole; 2003.

25. Cola PC, Gatto AR, Silva RG, Schelp AO, Henry MACA. Reabilitação em Disfagia Orofaríngea Neurogênica: sabor azedo e temperatura fria. Rev CEFAC. 2008;10(2):200-5.

26. Daniels SK, Brailey K, Priestly DH, Herrington LR, Weisberg LA, Foundas AL Aspiration in patients with acute stroke. Arch Phys Med Rehabil. 1998;79:14-9.

27. Leder SB. Gag reflex and dysphagia. Head-Neck. 1996;18:138-41.

28. Bleanch NR. The gag reflex and aspiration: a retrospective analysis of 120 patients assessed by videofluoroscopy. Clin. Otoryngol.1993; 18:303-307.

29. Buchholz D, Neumann S, Bartolome G,Prosiegel M. Swallowing therapy of neurologic patients: Correlation of outcome with pretreatment variables and therapeutic methods. Dysphagia. 1995; 10(1):1-5.

30. Rosenbek JC, Robbins J, Fishback B, Lecine RL. The effects of thermal aplication on dysphagia after stroke. J Speech Hear Res. 1991;34:1257-68.

31. Cola PC, Gatto AR, Silva RG, Spadotto AA, Schelp AO, Henry MAA. The influence of sour taste and cold temperature on pharyngeal transit time in cerebral vascular accident patients. Arq Gastroenterol. 2010;47(1):18-21.

32. Leonard R, McKenzie S. Hyoid-bolus transit latencies in nomral swallow. Dysphagia. 2006;21:183-90.

33. Vale-Prodomo LP. Caracterização videofluoroscópica da fase faríngea da deglutição [tese]. São Paulo Carlos (SP): Fundação Antônio Prudente; 2010.115p.

34. Alvite MFL, Lopes RLC, Costa MMB. Estimulação mecânico-térmica dos pilares palatoglosso. Arq Gastroenterol. 2007;44(3):221-6.

35. Ali GN, Land TM, Wallace KL, DeCarle DJ, Cook IJS. Influence of cold stimulation on the normal pharyngeal swallow response. Dysphagia. 1996;11:2-8. 